\title{
Retinal Vascular Changes with Non-Arteritis Anterior Ischemic Optic Neuropathy Assessed with IVAN Analysis
}

\section{Longli Zhang}

Tianjin medical university eye hospital

Kaiwen Hei

Tianjin Medical University Eye Hospital

Yifeng Ke

Tianjin Medical University Eye Hospital

Heng Zhang

Tianjin Medical University Eye Hospital

Xiaorong Li

Tianjin Medical University Eye Hospital

Qianhui Yang ( $\nabla$ qianh_1108@163.com )

Tianjin Medical University Eye Hospital https://orcid.org/0000-0001-6784-1742

Research article

Keywords: NAION, retinal vessel caliber, IVAN

Posted Date: August 12th, 2020

DOI: https://doi.org/10.21203/rs.3.rs-46700/v1

License: (1) This work is licensed under a Creative Commons Attribution 4.0 International License.

Read Full License 


\section{Abstract \\ Background}

To assess the vascular changes associated with non-arteritis anterior ischemic optic neuropathy (NAION) by using integrative vessel analysis (IVAN) and risk factors associated with NAION.

\section{Methods}

We performed a case-control study of 120 patients, including 40 NAION patients during July 2015 to July 2019. Patients were divided into Normal, hypertension and NAION groups. IVAN was conducted to evaluate the caliber of retinal vessels. In addition, we also analyzed risk factors (age, gender and BMI) to identify their association with NAION.

\section{Results}

84 women and 36 men were involved in our study, the average age was $58 \pm 9.98$ years. CRAE, CRVE and AVR in the whole patients were $154.54 \pm 21.53 \mu \mathrm{m}, 252.22 \pm 15.88 \mu \mathrm{m}$ and 0.64 , respectively. ANOVA analysis showed significant difference of CRAE $[F(2,116)=4.203, p=0.017], \operatorname{CRVE}[F(2,116)=49.91, p<$ 0.001] and AVR $[F(2,116)=13.81, p<0.0001]$ between each group, NAION group had wider CRAE and CRVE, while smaller AVR. BMI value showed negative correlation with CRAE in NAION group, while positively with CRVE.

\section{Conclusion}

Retinal vascular caliber can be used as an indicator to evaluate the NAION. Our study suggested that an assessment of retinal vascular caliber may offer insights into the development of NAION.

\section{Background}

Non-arteritis optic neuropathy (NAION) is one of the most common disease that influences the patients over 50 years old and causes irreversible visual loss[1]. Although NAION is a major cause of optic neuropathy except glaucoma, its pathogenesis, clinical characteristics and treatments still remain controversial[2]. Some researchers[1, 3, 4] considered a disk at risk (defined as a crowded small opticnerve head with a small physiological cup) may be a major risk for NAION's development. In addition, poor optic nerve head blood supply, location of posterior ciliary artery watershed zones, ciliary artery disease etc. are some of the considered local risk factor of NAION $[5,6]$. Furthermore, several systemic risk factors were thought to be associated with NAION, including arterial hypertension, diabetes mellitus (DM), arterial hypotension, hypercholesterolemia, stroke, ischemic heart disease, tobacco use and so on[7-9]. 
Progressions in digital retinal photography and software have made it more convenient for us to measure the characteristics of vessels in retinal[10,11]. IVAN is a software designed by University of Wisconsin, which could measure retinal vessel caliber by using fundus photographs[12]. Since researchers considered NAION as a disease which results from vascular insufficiency[13, 14], we assumed that vascular diameter is involved into pathophysiology of NAION.

By searching the database on the Internet, we found only few papers studied about risk factor of NAION. Also, this is an innovative research that explore numerous risk factors of NAION in different groups. In this study, we measured retinal vessel caliber from fundus pictures by using IVAN to assess its relevance to the progression of NAION. Besides, we also value other factors to explore their influences on the disease.

\section{Methods}

\section{Study population}

Tianjin Medical University Eye Hospital approved this study. All the patients involved in our study presented to Tianjin Medical University Eye Hospital service between July 2015 and July 2019.

We categorized the patients into three groups when they were in the outpatient clinic: normal group (Normal), hypertension group (Hyper) and NAION group (NAION). Grouping criteria are as below a) Patients without any systematic or retina diseases were included into our Normal group. This group comprised subjects with BCVA $>20 / 63, I O P<21 \mathrm{mmHg}$, an open angle and normal optic disc appearance on fundus examination, there were no abnormities in anterior chamber. The degree of opacity of the lens should allow us to take clear photos. b) Hyper group consisted patients with hypertension $(<120 \mathrm{mmHg}$ Systolic BP (SBP) and $<80 \mathrm{mmHg}$ Diastolic BP (DBP)). The Inclusion criteria for this group was that patients should had diagnosis of hypertension from a physician and did not have any other systematic diseases, such as coronary heart disease, stroke, diabetes mellitus and so on. Besides, criteria for diagnosing NAION were 1) acute, painless vision loss in 2 weeks; 2) optic disc edema with or without superficial hemorrhage.

1120 eyes from 120 patients (69 women, 51 men) were included in our research. Patients underwent a thoroughly ophthalmic evaluation, including best-corrected visual acuity (BCVA), intraocular pressure (IOP) with a noncontact pneumatic tonometer (Canon T-2; Canon, Tokyo), slip-lamp biomicroscopy and fundus examination. Other imaging examination including OCT, fluorescein angiography (FA) and indocyanine green angiography were performed depended on the patients' situation. For NAION patients, we performed OCT, FA, indocyanine green angiography and visual fields test routinely. At last, medical history such as age, gender, BMI were also recorded to evaluate their relevance with NAION.

\section{Retinal Fundus Pictures and Vessels' calculation}


Fundus pictures were taken without dilating the pupils: a $30^{\circ}$ color fundus picture of the eye centered on the disc were taken. We measured the caliber of vessels in patients' retina by using IVAN (University of Wisconsin, Madison) in fundus pictures from camera[15]. Briefly, the IVAN protocol required that vessel diameters should away from the six largest arterioles and six largest venules located in a zone, where 0.5 to 1.0 disc diameters from the disc margin. The measurement was performed by two ophthalmologists, who were masked to the characteristics of patients.

\section{Ethics Statement}

The institutional review board of Tianjin Medical University approved this clinical study protocol, and the protocols also adhered to Declaration of Helsinki. Besides, an oral informed consent was obtained from the patients after an explanation of the procedures and purpose of the examinations.

\section{Statistical Analysis}

All the statistical analyses in this study were conducted by using SPSS statistics version 19.0 (SPSS Inc., Chicago, IL). Our data were presented as mean \pm standard deviations. We performed one-way analysis of variance (ANOVA) for comparisons of parametric variables, after that a post hoc comparisons using the Tukey HSD test was performed to compare difference between each group.

We performed the univariate analysis with the Spearman's rank correlation coefficient tests. The significance of the correlations between the CRAE and CRVO, were determined relative to the systematic factors. A $P$ value of $<0.05$ was considered statistically significant.

\section{Results}

The baseline characteristics of the patients were summarized in Table 1. We divided the patients into three groups: Normal group (Normal), hypertension group (Hyper) and NAION group (NAION). 120 patients ( 69 women and $51 \mathrm{men}$ ) were included in our study. The average age ( \pm standard deviations) was $58 \pm 9.98$ years for the involved patients, and $57 \pm 12$ years, $56 \pm 8.01$ years, $58 \pm 11.4$ years for Normal, Hyper, NAION group, respectively. Figure 1 showed representative pictures for each group. There were no difference of age and gender in three groups from baseline. 
Table 1

Baseline Characteristics of Involved Patients

\begin{tabular}{|lllll|}
\hline Characteristics & $\begin{array}{l}\text { Total participants } \\
(\mathbf{n = 1 2 0 ) ;} \\
\begin{array}{l}\text { Mean } \pm \text { standard } \\
\text { deviation }\end{array}\end{array}$ & $\begin{array}{l}\text { Normal } \\
\text { participants }(n=)\end{array}$ & $\begin{array}{l}\text { Hypertension } \\
\text { Participants }(\mathbf{n}=40)\end{array}$ & $\begin{array}{l}\text { NAION } \\
\text { participants } \\
(\mathbf{n}=40)\end{array}$ \\
\hline Age, year & $58 \pm 9.98$ & $53 \pm 10.04$ & $56 \pm 8.01$ & $58 \pm 11.4$ \\
\hline $\begin{array}{l}\text { Gender, } \\
\text { female\% }\end{array}$ & $69,57.5 \%$ & $29,72.5 \%$ & $26,65 \%$ & $14,35 \%$ \\
\hline CRAE, $\mu \mathrm{m}$ & $154.54 \pm 21.53$ & $150.05 \pm 15.12$ & $154.05 \pm 11.72$ & $159.6 \pm$ \\
\hline CRVE, $\mu \mathrm{m}$ & $252.22 \pm 15.88$ & $242.26 \pm 14.53$ & $237.6 \pm 13.98$ & $277.17 \pm$ \\
\hline CRAE/CRVE & 0.64 & 0.676 & 0.646 & 26.58 \\
\hline
\end{tabular}

\section{Quantification of CRAE, CRVE and AVR}

We measured the CRAE, CRVE and CRAE/CRVE (AVR) in each group, representative pictures were showed in Fig. 2. The CRAE, CRVE and AVR in the whole patients were $154.54 \pm 21.53 \mu \mathrm{m}, 252.22 \pm 15.88 \mu \mathrm{m}$ and 0.64, respectively. In the Normal group, the CRAE, CRVE and AVR were $154.05 \pm 15.52 \mu \mathrm{m}, 235.49 \pm$ $13.87 \mu \mathrm{m}$ and 0.57 , respectively. The result in Hyper group of CRAE, CRVE and AVR were $150.05 \pm$ $15.03 \mu \mathrm{m}, 242.26 \pm 14.44 \mu \mathrm{m}$ and 0.545 , respectively. While CRAE, CRVE and AVR in NAION group were $159.6 \pm 17.13 \mu \mathrm{m}, 277.17 \pm 26.58 \mu \mathrm{m}$ and 0.598 , respectively venules are in blue. The measured area of retinal vascular caliber was standardized and defined as the showed region from 0.5 to 2.0 disc diameters away from the disc margin. A, C: measurement of vascular caliber. B, D: calibers measured result in IVAN software.

\section{Analysis of Differences of Vessels Caliber between Groups.}

A one-way between subjects' ANOVA was conducted to compare the retinal vessel caliber between 3 different groups (Fig. 3). There was a significant difference of CRAE at $p<0.05$ level for 3 groups [F $(2,116)=4.203, p=0.017]$. Post hoc comparisons showed that the CRAE was significantly larger in NAION group than it was in Hyper group $(M=-9.572, S D=3.315 ; 159.6$ vs. $150.05 \mu \mathrm{m})$, while there was no difference between Normal and Hyper group ( $M=4.021 \mathrm{SD}=3.36 ; 154.05 \mathrm{vs} .150 .05 \mu \mathrm{m})$. Also, no significant difference was found in NAION and Hyper group ( $M=-5.551$ SD $=3.336 ; 159.6$ vs.150.05 $\mu \mathrm{m})$.

Moreover, there was a significant difference of CRVE between 3 groups $[F(2,116)=49.91, p<0.001]$. The post hoc comparisons showed that the CRVE was significantly different between Hyper and NAION group $(M=-39.57, S D=4.344 ; 237.6$ vs.277.17 $\mu \mathrm{m})$, Normal and NAION group $(M=-34.91, S D=4.316 ; 242.26$ vs. $277.17 \mu \mathrm{m})$. CRVE in NAION group showed wider than other groups. While the results of comparison 
between Normal and Hyper group was not significantly different $(M=-4.666, S D=4.344 ; 242.26$ vs. $237.6 \mu \mathrm{m})$

Additionally, we also found a significant difference of AVR at $p<0.05$ level for 3 groups $[F(2,116)=13.81$, $p<0.0001$ ]. The post hoc comparisons showed AVR between Normal and NAION group was significantly different $(M=-0.078, S D=0.014 ; 0.676$ vs. 0.598$)$, moreover AVR between Hyper and NAION group showed the same result $(M=-0.048, S D=0.015 ; 0.646$ vs. 0.598$)$. Nonetheless the AVR between Normal and Hyper group showed no difference.

\section{Correlation between Retinal Vessel Caliber and Systemic Factors}

Associations of age and gender with CRAE and CRVE for each group are shown in Table 2. Central retinal artery caliber may correlate inversely with age in Normal $(r=-0.140, p=0.396)$ and Hyper group $(r=-0.082$, $p=0.616)$, while in NAION group, the CRAE was correlated positively $(r=0.110, p=0.499)$. The CRAE was correlated positively with male gender in three groups (Normal: $\mathrm{r}=0.001, p=0.994$; Hyper: $\mathrm{r}=0.222, p=$ 0.118; NAION: $r=0.047, p=0.770$ ).

Central retinal vein caliber may correlate inversely with age in three group: Normal: $r=-0.110, p=0.504$; Hyper: $r=-0.122, p=0.454$; NAION: $r=-0.196, p=0.225$. Furthermore, the CRVE was correlated with female gender in three groups (Normal: $r=-0.156, p=0.343$; Hyper: $r=-0.215, p=0.184$; NAION: $r=-0.08, p=0.622$ ).

Table 2

Association of Retinal Vessel Caliber with Systemic Factors

\begin{tabular}{|llll|}
\hline Systemic Factors r (P value) & Normal & Hypertension & NAION \\
\hline CRAE & & & \\
\hline Age, year & $-0.140(0.396)$ & $-0.082(0.616)$ & $0.110(0.499)$ \\
\hline Gender & $0.001(0.994)$ & $0.222(0.188)$ & $0.047(0.770)$ \\
BMI & $-0.10(0.32)$ & $0.03(0.79)$ & $-0.04(0.04)$ \\
CRVE & & & \\
Age, year & $-0.110(0.504)$ & $-0.122(0.454)$ & $-0.196(0.225)$ \\
\hline Gender & $-0.156(0.343)$ & $-0.215(0.184)$ & $-0.08(0.622)$ \\
\hline BMI & $0.104(0.29)$ & $0.016(0.95)$ & $0.01(0.95)$ \\
\hline
\end{tabular}

CRAE: central retinal artery equivalent

CRVE: central retinal vein equivalent

We also calculate the correlation between $\mathrm{BMI}$ and retinal vessel caliber in each group: in Normal and Hyper group, the BMI showed there were no correlations with CRAE (Normal: $r=-0.10, p=0.32$; Hyper: $r=$ 
0.03, $p=0.79$ ), CRVE (Normal: $r=0.104, p=0.29$; Hyper: $r=0.016, p=0.95$ ), while in NAION group, the result indicated that the BMI was correlate negatively with CRAE ( $r=-0.10, p=-0.04)$, while CRVE was positively correlated with BMI $(r=0.95, p=0.01)$.

\section{Discussion}

Totally 120 patients were involved in our study. Our research compared the caliber and their ratio in different groups of patients, NAION group has widest vessels' caliber. Also, we found negative correlation between the BMI value and CRAE, while positively correlation with CRVE, we assumed the obesity may have relationship with retinal vessels' calibers. Nowadays, several methods have been used to measure the retinal vascular caliber from the fundus images[16-18]. The IVAN method can be used as a "marker" for the systemic factors, such as age, hypertension, diabetes mellitus and physical activity[19].

When comparing CRAE, we found that CARE in NAION group was significantly increased than that in Normal group. The result was not showed in other papers previously. We assumed this artery changes may be caused by "hypoxia" status of the retinal environment in NAION. When the tissue is hypoxic, hypoxic vasodilation appears to increase the perfusion of blood to the tissue[20]. In response to decrease of ATP, $\mathrm{K}_{\text {ATP }}$ channels of vascular smooth muscle cells opens, inducing the vasodilation[21].

While the result of comparing CRAE showed no difference between Normal and Hyper group, we can find mean value of CRAE in Hyper group was smaller than Normal group. The narrowing trend had been confirmed by numerous studies[22, 23]. Comparing with other systemic factors, retinal arteriolar narrowing has been reported to have the strongest relationship with the hypertension[24].

Comparing CRVE in 3 groups showed NAION group had the largest retina venous dimension. This result was consistent with previous study of NAION. Some researchers considered most of the NAION Patients have severe and acute optic disk edema, this abnormal changes may some degree of restriction of central retinal venous return, elevating the retinal venous pressure, thus leading the vascular dilation[25]. While the analysis showed no significantly difference between Hyper and Normal group, the mean value of CRVE in Hyper group was higher than it was in Normal group. This result was consistent with Jonas et al.'s study retinal vein diameters are associated with higher blood pressure [26].

The AVR result showed the ratio in NAION group was the smallest among three groups. This demonstrated the venous dilation was greater in NAION group than the other two groups. The result was also consistent with previous studies. In the Atherosclerosis Risk In Communities (ARIC) study, nonspecific inflammatory factors were associated with smaller AVR[27]. Researchers considered the result was associated to arteriolar narrowing, while later it was confirmed to be related to venular dilation[28]. While Wong TY et al. found no association between nonspecific inflammatory markers and vessel diameters in the Cardiovascular Health Study (CHS)[29].

Caliber of retina vessels in NAION group was greater than that in other groups, which may be associated with the ischemia state of the NAION patients[30]. For the unknown cause of the disease, presence of a 
small crowded optic disc and systemic comorbidities are the two most acceptable reasons for the disease[31]. Studies had showed that NAION patients have higher prevalence of "having absent or small cup", this unique structure may result in crowding of optic nerve fibers and lead a restricted space in the optic disc[32, 33]. Ischemia state stimulate the vessels dilate so the tissues could gain enough oxygen as this is a compensatory response.

Nevertheless, numerous researchers were trying to figure out the pathogenesis of NAION, to our knowledge, the mechanisms of NAION are still unknow. Some studies showed that a small cup to disc ratio was essential for the ANION development[34,35]. While other researchers considered that other factors such as optic nerve drusen and papilledema, which could lead to a "crowding optic nerve head", may be crucial to the disease[36]. Since the results of studies remain variable, we performed the analysis to find association between disease and factors, the retinal vessels caliber changes in NAION.

Age, gender and BMI were discussed as risk factors of NAION in many studies. Melson et al. considered all the patients older than 50 with ischemic optic neuropathy should be thought of giant-cell arteritis[37]. And older people have narrower vascular caliber has been widely demonstrated across numerous studies and populations $[24,38,39]$. A previous research showed that greater BMI was related to the narrower retinal arteriolar caliber in children of 6 years old[40], on the contrary, Xiao et al.'s research showed there were no correlation between the retinal caliber and BMI[41]. They found greater body fat deposition was related with narrower retinal arterioles and wider venules, while the result only present in 12-19 years old children, not in younger children, indicating the higher BMI may associate with microvasculature in puberty children. These results were consistent with ours: CRAE was narrower in patients with higher BMI, while CRVE showed wider in higher BMI patients.

Currently, the diabetes mellitus (DM) status was considered one of the major risk factors of vascular disease[42], the status can influence the retinal vessels' caliber. Li et al. considered mothers developed gestational diabetes mellitus (GDM) had narrower caliber, reduced fractal dimension and larger branching angle, suggesting the hyperglycemia may cause abnormalities of small vessels[43]. The vaso-constrictive effect presumed to be caused by hyperglycemia status of the DM patient[44]. While in this study, we didn't include the DM status into our research for the following reasons. On the one hand, the DM status may influence the measurement of the vessel's caliber, our study mainly focused on the NAION and tried to avoid any interference factors. On the other hand, if we involved three diseases into our study (NAION, hypertension and DM), the incidence of NAION may be influenced.

Our results may have clinical applications to NAION. First of all, our study provided further information for the assessment of vascular caliber in NAION patients. The CRAE, CRVE and AVR measurement may act as a marker for the disease. Second, more attention should be paid for the patients with higher vascular caliber, especially venular dilation (higher AVR). Third, this data may act as a tool added therapeutic value in the management of patients with NAION, this need more data of after-curing patients.

However, limitations of our study still existed. First, our study only included Chinese patients, more ethnic groups were needed to make the study more authentic. Second, our study has 120 involved patients, 
more patients were needed for the further study. At last, in hypertension group DM's duration and stages should be considered. We set the hypertension group to compare whether the caliber changes were primary or secondary to the disease, changes of blood vessels in hypertension patients were secondary to hypertension, we assumed part of caliber changes in NAION may have similar pathophysiology with hypertension.

\section{Conclusions:}

In summary, the result of our study indicated that retinal vascular caliber is related to BMI, obesity maybe a risk factor to the NAION patients. Arteriolar narrowing is related to hypertension, while venular dilation and higher AVR was associated NAION patients. Our result suggested an assessment of the CRAE, CRVE and AVR may be a marker for the NAION patients and more attention should be paid for the subclinical vascular abnormalities.

\section{Abbreviations}

NAION: non-arteritis anterior ischemic optic neuropathy; IVAN: integrative vessel analysis; CRAE: central retinal artery equivalent; CRVE: central retinal vein equivalent; DM: diabetes mellitus; GDM: gestational diabetes mellitus; AVR: artery versus vein caliber

\section{Declarations}

\section{Ethics approval and consent to participate!}

The institutional review board of Tianjin Medical University approved this clinical study protocol. Each participant in our study was stated and signed the consent for participation.

\section{Availability of data and material:}

available to supply the raw data if needed.

\section{Acknowledgements:}

Not applicable.

\section{Funding:}

Tianjin Clinical Key Discipline Project (TJLCZDXKM009)

\section{Consent for publication:}

Not applicable

Competing interests: 
None.

Authors' contributions:

$\mathrm{LL} \mathrm{Z}$ and QH Y conceived the idea of the study and write the paper, $\mathrm{KW} \mathrm{H}, \mathrm{YF} \mathrm{K}$ and $\mathrm{HZ}$ collect the data, $X R L$ analyzed the data and make modification of the manuscript.

\section{References}

1. Biousse V, Newman NJ: Ischemic Optic Neuropathies. N Engl J Med 2015, 373(17):1677.

2. Hayreh SS: Ischemic optic neuropathies - where are we now? Graefes Arch Clin Exp Ophthalmol 2013, 251(8):1873-1884.

3. Pomeranz HD, Smith KH, Hart WM, Jr., Egan RA: Sildenafil-associated nonarteritic anterior ischemic optic neuropathy. Ophthalmology 2002, 109(3):584-587.

4. Burde RM: Optic disk risk factors for nonarteritic anterior ischemic optic neuropathy. $A m \mathrm{~J}$ Ophthalmol 1993, 116(6):759-764.

5. Hayreh SS: Blood flow in the optic nerve head and factors that may influence it. Prog Retin Eye Res 2001, 20(5):595-624.

6. Wilhelm H, Beisse F, Ruther K: [Non-Arteritic Ischemic Optic Neuropathy (NAION)]. Klin MonbI Augenheilkd 2015, 232(11):1260-1269.

7. Hayreh SS, Joos KM, Podhajsky PA, Long CR: Systemic diseases associated with nonarteritic anterior ischemic optic neuropathy. Am J Ophthalmol 1994, 118(6):766-780.

8. Hayreh SS, Podhajsky P, Zimmerman MB: Role of nocturnal arterial hypotension in optic nerve head ischemic disorders. Ophthalmologica 1999, 213(2):76-96.

9. Archer EL, Pepin S: Obstructive sleep apnea and nonarteritic anterior ischemic optic neuropathy: evidence for an association. J Clin Sleep Med 2013, 9(6):613-618.

10. Hussain N, Edraki M, Tahhan R, Sanalkumar N, Kenz S, Akasha NK, Mtemererwa B, Mohammed N: Telemedicine for diabetic retinopathy screening using an ultra-widefield fundus camera. Clin Ophthalmol 2017, 11:1477-1482.

11. Li L, Zhang P, Liu H, Liu YH, Gao L: EVALUATION OF MULTISPECTRAL IMAGING IN DIAGNOSING DIABETIC RETINOPATHY. Retina 2018.

12. Wong TY, Islam FM, Klein R, Klein BE, Cotch MF, Castro C, Sharrett AR, Shahar E: Retinal vascular caliber, cardiovascular risk factors, and inflammation: the multi-ethnic study of atherosclerosis (MESA). Invest Ophthalmol Vis Sci 2006, 47(6):2341-2350.

13. Callizo J, Feltgen N, Ammermann A, Ganser J, Bemme S, Bertelmann T, Pfeiffer S, Duvinage A, Groschel $\mathrm{K}$, Hoerauf $\mathrm{H}$ et al: Atrial fibrillation in retinal vascular occlusion disease and non-arteritic anterior ischemic optic neuropathy. PLoS One 2017, 12(8):e0181766.

14. Rootman J, Butler D: Ischaemic optic neuropathy-a combined mechanism. Br J Ophthalmo/ 1980, 64(11):826-831. 
15. Hubbard LD, Brothers Rj Fau - King WN, King Wn Fau - Clegg LX, Clegg Lx Fau - Klein R, Klein R Fau Cooper LS, Cooper Ls Fau - Sharrett AR, Sharrett Ar Fau - Davis MD, Davis Md Fau - Cai J, Cai J: Methods for evaluation of retinal microvascular abnormalities associated with hypertension/sclerosis in the Atherosclerosis Risk in Communities Study. Ophthalmology 1999, 106(12):2269-2280.

16. Rassam SM, Patel V Fau - Brinchmann-Hansen O, Brinchmann-Hansen O Fau - Engvold O, Engvold $O$ Fau - Kohner EM, Kohner EM: Accurate vessel width measurement from fundus photographs: a new concept. Br J Ophthalmol 1994, 78(1):24-29.

17. Suzuki Y: Direct measurement of retinal vessel diameter: comparison with microdensitometric methods based on fundus photographs. Surv Ophthalmo/ 1995(39 Suppl 1):S57-65.

18. Wu DC, Schwartz B Fau - Schwoerer J, Schwoerer J Fau - Banwatt R, Banwatt R: Retinal blood vessel width measured on color fundus photographs by image analysis. Acta Ophthalmol Scand Suppl 1995, 215:33-40.

19. Ikram MK, Ong Yt Fau - Cheung CY, Cheung Cy Fau - Wong TY, Wong TY: Retinal vascular caliber measurements: clinical significance, current knowledge and future perspectives. Ophthalmologica 2013, 229(3):125-136.

20. Dart C, Standen NB: Activation of ATP-dependent K+ channels by hypoxia in smooth muscle cells isolated from the pig coronary artery. J Physiol 1995, 483(Pt1):29-39.

21. Peers $C$, Kemp PJ: Acute oxygen sensing: diverse but convergent mechanisms in airway and arterial chemoreceptors. Respir Res 2001, 2(3):145-149.

22. Ikram MK, de Jong Fj Fau - Vingerling JR, Vingerling Jr Fau - Witteman JCM, Witteman Jc Fau Hofman A, Hofman A Fau - Breteler MMB, Breteler Mm Fau - de Jong PTVM, de Jong PT: Are retinal arteriolar or venular diameters associated with markers for cardiovascular disorders? The Rotterdam Study. Invest Ophthalmol Vis Sci 2004, 45(7):2129-2134.

23. Gepstein R, Rosman Y Fau - Rechtman E, Rechtman E Fau - Koren-Morag N, Koren-Morag N Fau Segev S, Segev S Fau - Assia E, Assia E Fau - Grossman E, Grossman E: Association of retinal microvascular caliber with blood pressure levels. Blood Press 2012, 21(3):191-196.

24. Wong TY, Klein R Fau - Klein BEK, Klein Be Fau - Meuer SM, Meuer Sm Fau - Hubbard LD, Hubbard LD: Retinal vessel diameters and their associations with age and blood pressure. Invest Ophthalmol Vis Sci 2003, 44(11):4644-4650.

25. Bernstein SL, Johnson Ma Fau - Miller NR, Miller NR: Nonarteritic anterior ischemic optic neuropathy (NAION) and its experimental models. Prog Retin Eye Res 2011, 30(3):167-187.

26. Jonas JB, Wang N, Wang S, Wang YX, You QS, Yang D, Wei WB, Xu L: Retinal vessel diameter and estimated cerebrospinal fluid pressure in arterial hypertension: the Beijing Eye Study. AM J Hypertens 2014, 27(9):1170-8

27. Klein R, Sharrett Ar Fau - Klein BE, Klein Be Fau - Chambless LE, Chambless Le Fau - Cooper LS, Cooper Ls Fau - Hubbard LD, Hubbard Ld Fau - Evans G, Evans G: Are retinal arteriolar abnormalities 
related to atherosclerosis?: The Atherosclerosis Risk in Communities Study. Arterioscler Thromb Vasc Biol 2000, 20(6):1644-1650.

28. Cooper LS, Wong Ty Fau - Klein R, Klein R Fau - Sharrett AR, Sharrett Ar Fau - Bryan RN, Bryan Rn Fau - Hubbard LD, Hubbard Ld Fau - Couper DJ, Couper Dj Fau - Heiss G, Heiss G Fau - Sorlie PD, Sorlie PD: Retinal microvascular abnormalities and MRI-defined subclinical cerebral infarction: the Atherosclerosis Risk in Communities Study. Stroke 2006, 37(1):82-86.

29. Klein R, Klein Be Fau - Knudtson MD, Knudtson Md Fau - Wong TY, Wong Ty Fau - Tsai MY, Tsai MY: Are inflammatory factors related to retinal vessel caliber? The Beaver Dam Eye Study. Arch Ophthalmol 2006, 124(1):87-94.

30. Distefano Ag Fau - Lam BL, Lam BL: Non-Arteritic Anterior Ischemic Optic Neuropathy in Pilots. Aerosp Med Hum Perform 2018, 89(11):1005-1007.

31. Hayreh SS: Management of ischemic optic neuropathies. Indian J Ophthalmo/ 2011, 59(2):123-136.

32. Beck RW, Servais Ge Fau - Hayreh SS, Hayreh SS: Anterior ischemic optic neuropathy. IX. Cup-to-disc ratio and its role in pathogenesis. Ophthalmology 1987, 94(11):1503-1508.

33. Hayreh SS, Zimmerman MB: Non-arteritic anterior ischemic optic neuropathy: role of systemic corticosteroid therapy. Graefes Arch Clin Exp Ophthalmol 2008, 246(7):1029-1046.

34. Doro S Fau - Lessell S, Lessell S: Cup-disc ratio and ischemic optic neuropathy. Arch Ophthalmol 1985, 103(8):1143-1144.

35. Lavin PJ: Optic disk risk factors for nonarteritic anterior ischemic optic neuropathy. Am J Ophthalmol 1994, 117(6):822.

36. Saito H, Tomidokoro A Fau - Tomita G, Tomita G Fau - Araie M, Araie M Fau - Wakakura M, Wakakura M: Optic disc and peripapillary morphology in unilateral nonarteritic anterior ischemic optic neuropathy and age- and refraction-matched normals. Ophthalmology 2008, 115(9):1585-1590.

37. Melson MR, Weyand Cm Fau - Newman NJ, Newman Nj Fau - Biousse V, Biousse V: The diagnosis of giant cell arteritis. Rev Neurol Dis 2007, 4(3):128-142.

38. Kawasaki R, Wang Jj Fau - Rochtchina E, Rochtchina E Fau - Taylor B, Taylor B Fau - Wong TY, Wong Ty Fau - Tominaga M, Tominaga M Fau - Kato T, Kato T Fau - Daimon M, Daimon M Fau - Oizumi T, Oizumi T Fau - Kawata S, Kawata S Fau - Kayama T et al: Cardiovascular risk factors and retinal microvascular signs in an adult Japanese population: the Funagata Study. Ophthalmology 2006, 113(8):1378-1384.

39. Klein R, Klein Be Fau - Moss SE, Moss Se Fau - Wong TY, Wong Ty Fau - Sharrett AR, Sharrett AR: Retinal vascular caliber in persons with type 2 diabetes: the Wisconsin Epidemiological Study of Diabetic Retinopathy: XX. Ophthalmology 2006, 113(9):1488-1498.

40. Taylor B, Rochtchina E Fau - Wang JJ, Wang Jj Fau - Wong TY, Wong Ty Fau - Heikal S, Heikal S Fau Saw SM, Saw Sm Fau - Mitchell P, Mitchell P: Body mass index and its effects on retinal vessel diameter in 6-year-old children. Int J Obes (Lond) 2007, 31(10):1527-1533.

41. Xiao W, Gong W, Chen Q, Ding X, Chang B, He M: Association between body composition and retinal vascular caliber in children and adolescents. Invest Ophthalmol Vis Sci 2014, 56(2):705-710. 
42. Szuszkiewicz-Garcia MM, Davidson JA: Cardiovascular disease in diabetes mellitus: risk factors and medical therapy. Endocrinol Metab Clin North Am 2014, 43(1):25-40.

43. Li LJ, Kramer M, Tapp RJ, Man RE, Lek N, Cai S, Yap F, Gluckman P, Tan KH, Chong YS et al: Gestational diabetes mellitus and retinal microvasculature. BMC Ophthalmo/2017, 17(1):4.

44. Benitez-Aguirre PZ, Sasongko Mb Fau - Craig ME, Craig Me Fau - Jenkins AJ, Jenkins Aj Fau Cusumano J, Cusumano J Fau - Cheung N, Cheung N Fau - Wong TY, Wong Ty Fau - Donaghue KC, Donaghue KC: Retinal vascular geometry predicts incident renal dysfunction in young people with type 1 diabetes. Diabetes Care 2012, 35(3):599-604.

\section{Figures}

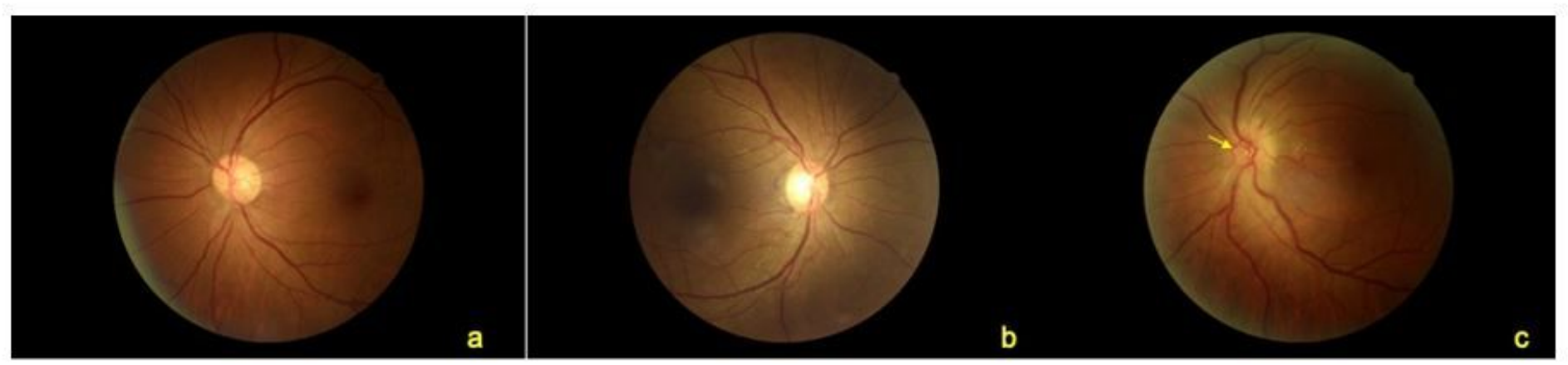

Figure 1

Fundus pictures depicting features of each group. a Fundus picture from a normal patient. b Fundus picture from a patient with hypertension. c Fundus picture from a NAION patient. The yellow arrow showed a small optic disc and an absent cup (disc at risk) 

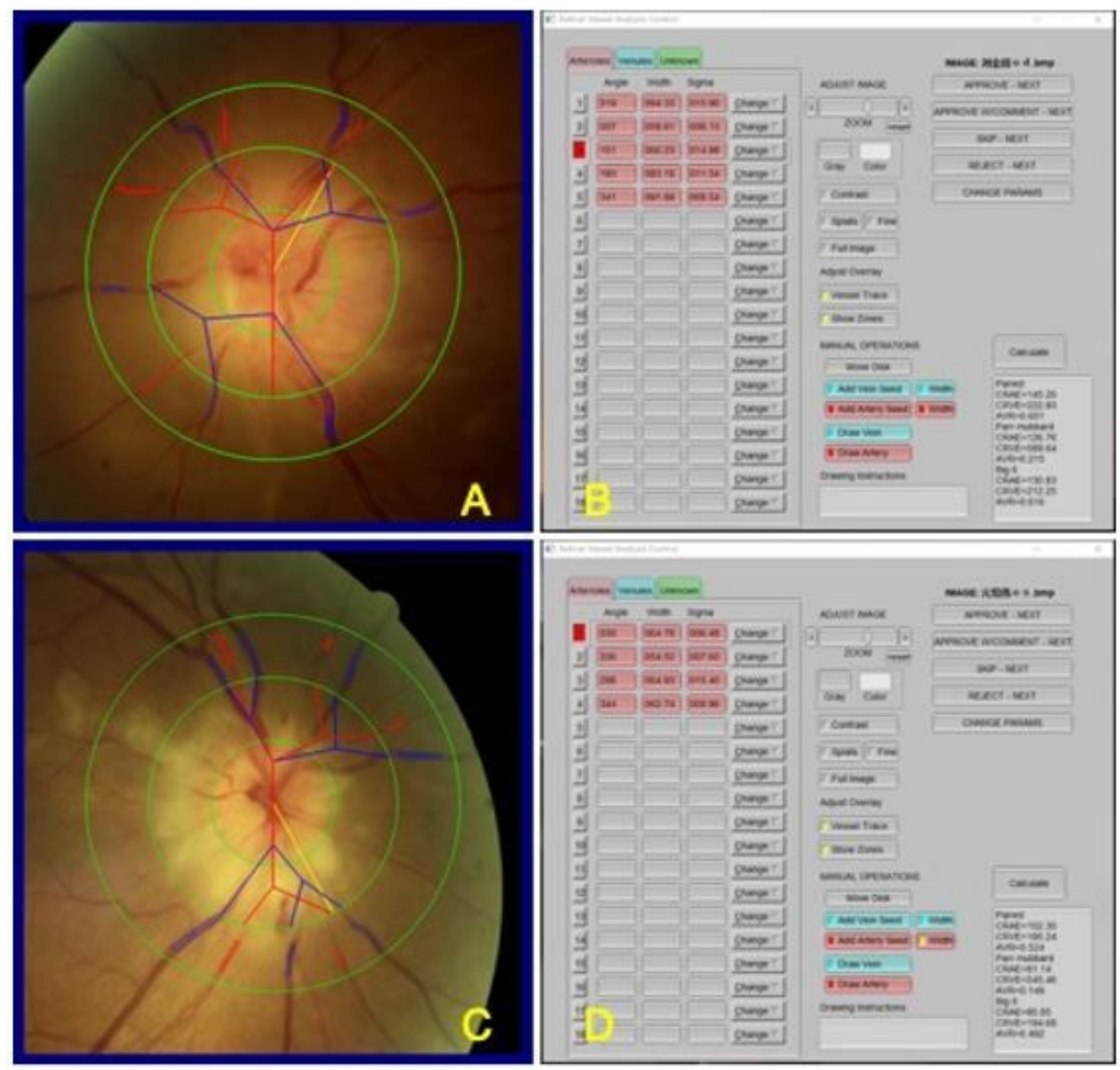

\section{Figure 2}

Representative IVAN measurement of vascular caliber. Arterioles are in red and the venules are in blue. The measured area of retinal vascular caliber was standardized and defined as the showed region from 0.5 to 2.0 disc diameters away from the disc margin. A, C: measurement of vascular caliber. B, D: calibers measured result in IVAN software. 


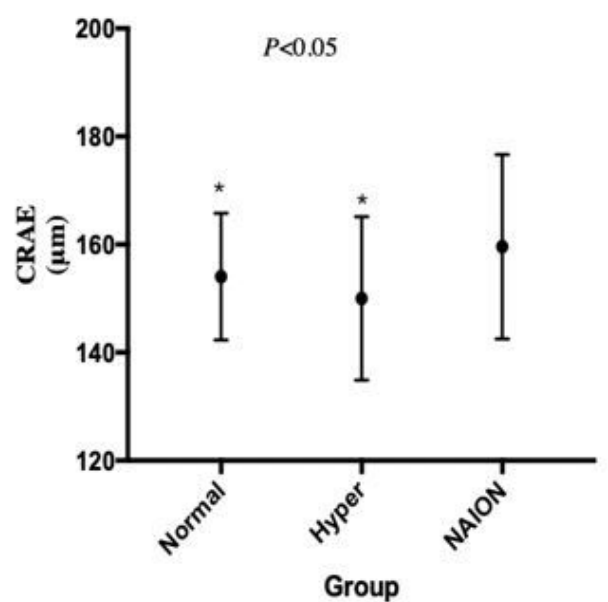

A

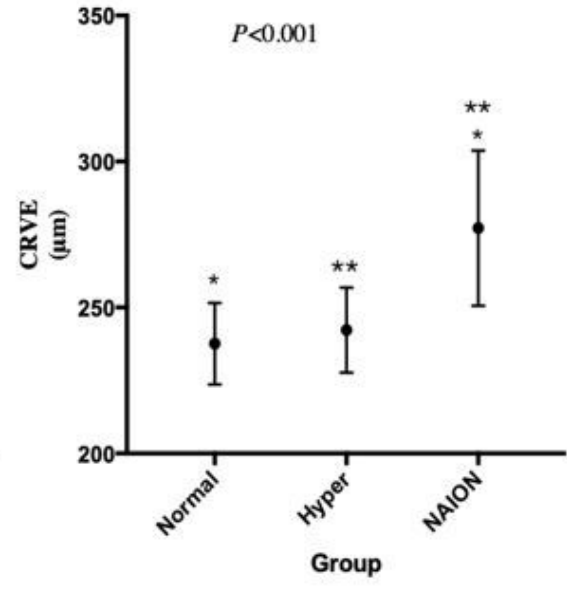

B

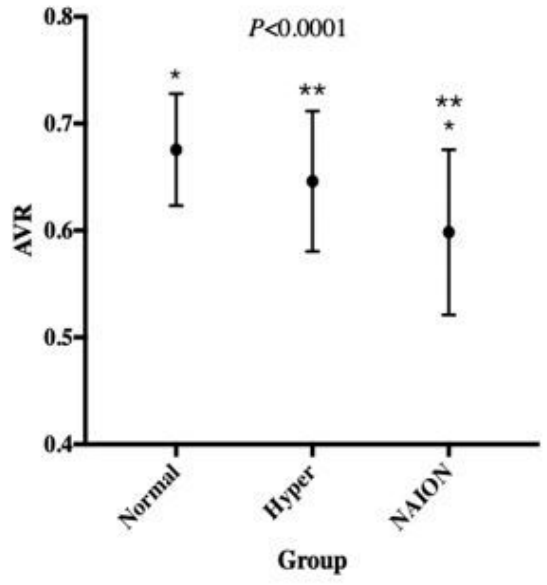

C

\section{Figure 3}

Distribution of retinal microvascular diameters. (A) CRAE comparison; (B) CRVE comparison; (C) AVR comparison. Data are mean micrometers and SD. *: statistically different, $p<0.05, * *$ : statistically different, $p<0.05$ 